\title{
Local-scale cross-correlation of seismic noise from the Calico fault experiment
}

\author{
Jian Zhang $\cdot$ Peter Gerstoft
}

Received: 27 November 2013/Accepted: 28 February 2014/Published online: 28 March 2014

(C) The Seismological Society of China, Institute of Geophysics, China Earthquake Administration and Springer-Verlag Berlin Heidelberg 2014

\begin{abstract}
Most studies of seismic noise cross-correlation (NCC) have focused on regional/continental scale imaging using empirical surface-wave Green's functions extracted from primary $(0.05-0.08 \mathrm{~Hz})$ and secondary $(0.1-0.16 \mathrm{~Hz})$ microseisms. In this work, we present the NCC results at higher frequencies $(>0.5 \mathrm{~Hz})$ from 6 months seismic noise recorded by a local array ( $\sim 4 \mathrm{~km}$ aperture) deployed along the Calico fault in the Mojave Desert, California. Both fast and slow propagating waves are observed from the NCC record-sections. We compare the NCCs from sensor pairs that share a common sensor with the records of a borehole shot located very close to this common sensor. The result shows a good match of the slow surface-wave arrivals, indicating that the NCC method is able to recover unbiased surface-wave Green's functions at local scales. The strong body-wave NCC component is caused by the $\mathrm{P}$ waves generated offshore California. Along a SW-NE profile across the fault, we observe apparent P-wave arrivals and their reflections, which can be explained by a low-velocityzone (LVZ) along the Calico fault. We calculate the LVZ width to be $\sim 2.3 \mathrm{~km}$, and the P-wave velocity reduction within the LVZ to be $\sim 35 \%$. These estimates are consistent with other evidence for a relatively wide LVZ along the Calico fault.
\end{abstract}

Keywords Cross-correlation - Seismic noise $\cdot$ LVZ . Body wave

J. Zhang $(\bowtie) \cdot$ P. Gerstoft

Marine Physical Laboratory, Scripps Institution of

Oceanography, University of California, San Diego, La Jolla, CA 92093, USA

e-mail: jessezhang.ucsd@gmail.com

\section{Introduction}

It has been established both theoretically and observationally that cross-correlation of diffuse wave fields can passively recover structure responses, i.e., Green's functions (e.g., Rickett and Claerbout 1999; Lobkis and Weaver 2001; Campillo and Paul 2003; Snieder 2004; Roux et al. 2004; Shapiro and Campillo 2004; Sabra et al. 2005a). In seismology, particularly, noise cross-correlation (NCC) allows the extraction of Green's functions in regions previously little/less covered due to the lack of earthquake sources, and thus has gained great success in imaging highresolution Earth's structures (e.g., Shapiro et al. 2005; Sabra et al. 2005b; Gerstoft et al. 2006; Yao et al. 2006; Yang et al. 2007; Lin et al. 2008; Bensen et al. 2008).

Most NCC applications to date have been at regional/ continental scales, focusing on the retrieval of surface-wave Green's functions from the primary $(\sim 0.05-0.08 \mathrm{~Hz})$ and secondary $(\sim 0.1-0.16 \mathrm{~Hz})$ microseisms driven by ocean waves. A few studies have presented the ability of the NCC method at small scales (on the order of $100 \mathrm{~m}$ or less) and/or for the frequencies of $3 \mathrm{~Hz}$ and above (Chavez-Garcia and Luzon, 2005; Gouedard et al. 2008; Halliday et al. 2008). However, studies at local scales (on the order of $0.1-1 \mathrm{~km}$ ) and/or the frequency band about $0.5-3 \mathrm{~Hz}$, which also are of interests in near-field exploration geophysics, are rare (Nuziata et al. 2009; De Nisco and Nunziata 2011). Unlike major microseism for regional scale NCC, noise at higher frequencies $(0.5-3 \mathrm{~Hz})$ is perhaps less coherent and requires longer time for NCC to converge. While local-scale deployments often operate in short time interval (days to months) and record only triggered events. Besides, specific modes of surface waves may not be well developed for nearfield waveforms at local scales, causing bias in dispersion analysis. Moreover, strong directional body waves often 


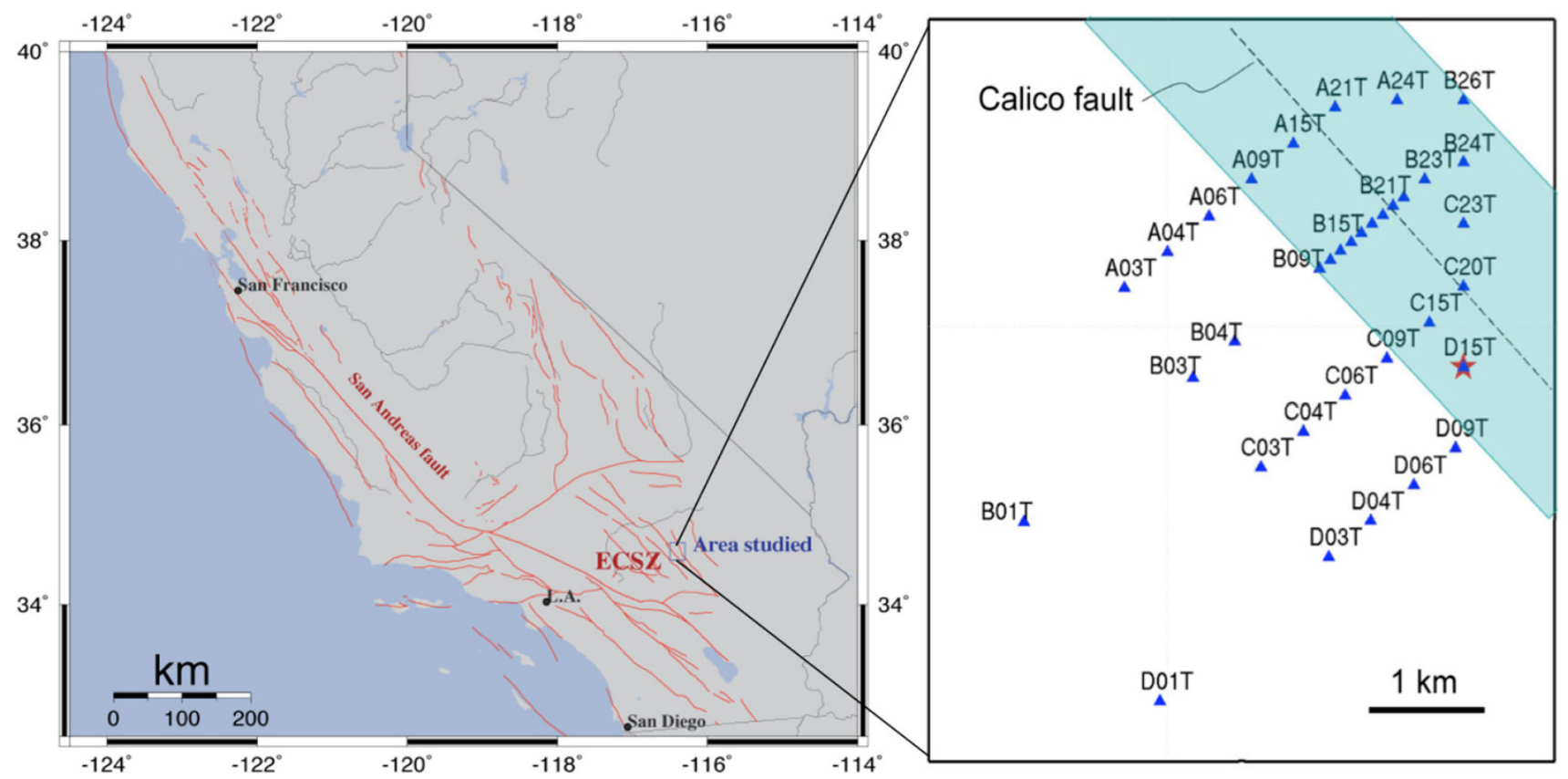

Fig. 1 Map of the California major fault systems and the Calico fault study area (left), as well as the array geometry (right). The fault traces are shown in red. ECSZ stands for the eastern California shear zone. The right panel shows sensor locations (triangles) and codes, a borehole shot (star), the Calico fault trace (dashed line), and the LVZ zone (shadow area)

exist at higher frequencies and cause apparent body-wave arrivals in NCC waveforms (e.g., Roux et al. 2005; Wang et al. 2010), which may contaminate Green's function retrieval.

In this paper, we focus on frequencies above $0.5 \mathrm{~Hz}$ and present NCC results using seismic noise recorded by a local-scale dense array ( $\sim 4 \mathrm{~km}$ aperture, see Fig. 1$)$, which was deployed along the Calico fault in the Mojave Desert, California. The data set is unique in terms of (1) local scale (a few km); (2) long recordings (6 months); and (3) co-location of a seismic sensor and a borehole shot, which allows direct comparison of the noise-based Green's functions with the shot arrivals. The goal of this paper is to show that despite the above difficulties, at local scales (1) reliable Green's functions can be recovered from NCCs, at least for slower phases; and (2) apparent body-wave arrivals can be used to study fault zone structures.

\section{Methods and data processing}

The idea of the NCC method is that in time domain, the time derivative of the NCC $C_{i j}\left(\boldsymbol{r}_{1}, \boldsymbol{r}_{2}, t\right)$ between two seismic sensors (sensor 1 at $\boldsymbol{r}_{1}$ recording the $i$ component, and sensor 2 at $\boldsymbol{r}_{2}$ recording the $j$ component) is related to the Green's function $G_{i j}\left(\boldsymbol{r}_{1} ; \boldsymbol{r}_{2}, t\right)$ by (Gerstoft et al. 2006): $\frac{\mathrm{d} C_{i j}\left(\boldsymbol{r}_{1}, \boldsymbol{r}_{2}, t\right)}{\mathrm{d} t} \approx-G_{i j}\left(\boldsymbol{r}_{1} ; \boldsymbol{r}_{2}, t\right)+G_{i j}\left(\boldsymbol{r}_{1} ; \boldsymbol{r}_{2},-t\right)$, where, $C_{i j}$ is calculated from the wave fields $v_{i}\left(\boldsymbol{r}_{1}, t\right)$ in direction $i$ at location $\boldsymbol{r}_{1}$ and $v_{j}\left(\boldsymbol{r}_{2}, t\right)$ in direction $j$ at location $\boldsymbol{r}_{2}$, i.e., $C_{i j}\left(\boldsymbol{r}_{1}, \boldsymbol{r}_{2}, t\right)=\int_{0}^{T} v_{i}\left(\boldsymbol{r}_{1}, \tau\right) v_{j}\left(\boldsymbol{r}_{2}, t+\tau\right) \mathrm{d} \tau$.

This relationship is established assuming a homogeneous distribution of sources surrounding the sensors. In practice, asymmetry of the positive and the negative part of the NCCs are observed, mainly due to uneven seismic noise source distributions (secondary causes may include possible asymmetric velocity and attenuation structure between sources and receivers (Liu and Ben-Zion 2013; Weaver 2013)). In most cases, however, bias in travel time estimates of the NCC-derived empirical Green's functions is found to be small. One may choose to average positive and negative parts of NCC functions, in order to obtain symmetric and signal-to-noise (SNR) enhanced NCCs. In this work, we focus on one-sided asymmetric NCCs because we have knowledge of dominant noise source directions.

We collect 6 months of the continuous three-component seismic records from 35 intermediate-period sensors (Guralp CMG-40T) shown in Fig. 1. Data from an active borehole shot $(30 \mathrm{~m}$ deep) are also used. The shot has nearly the same location as the sensor D15T. In order to perform NCC analysis, we first filter the data with a frequency band-pass of $0.05-20 \mathrm{~Hz}$ to remove the low-frequency trends. Secondly, we truncate the data with amplitudes above the level of the standard deviation of the background noise to reduce the effect of large transient events. The data are then normalized in frequency domain 


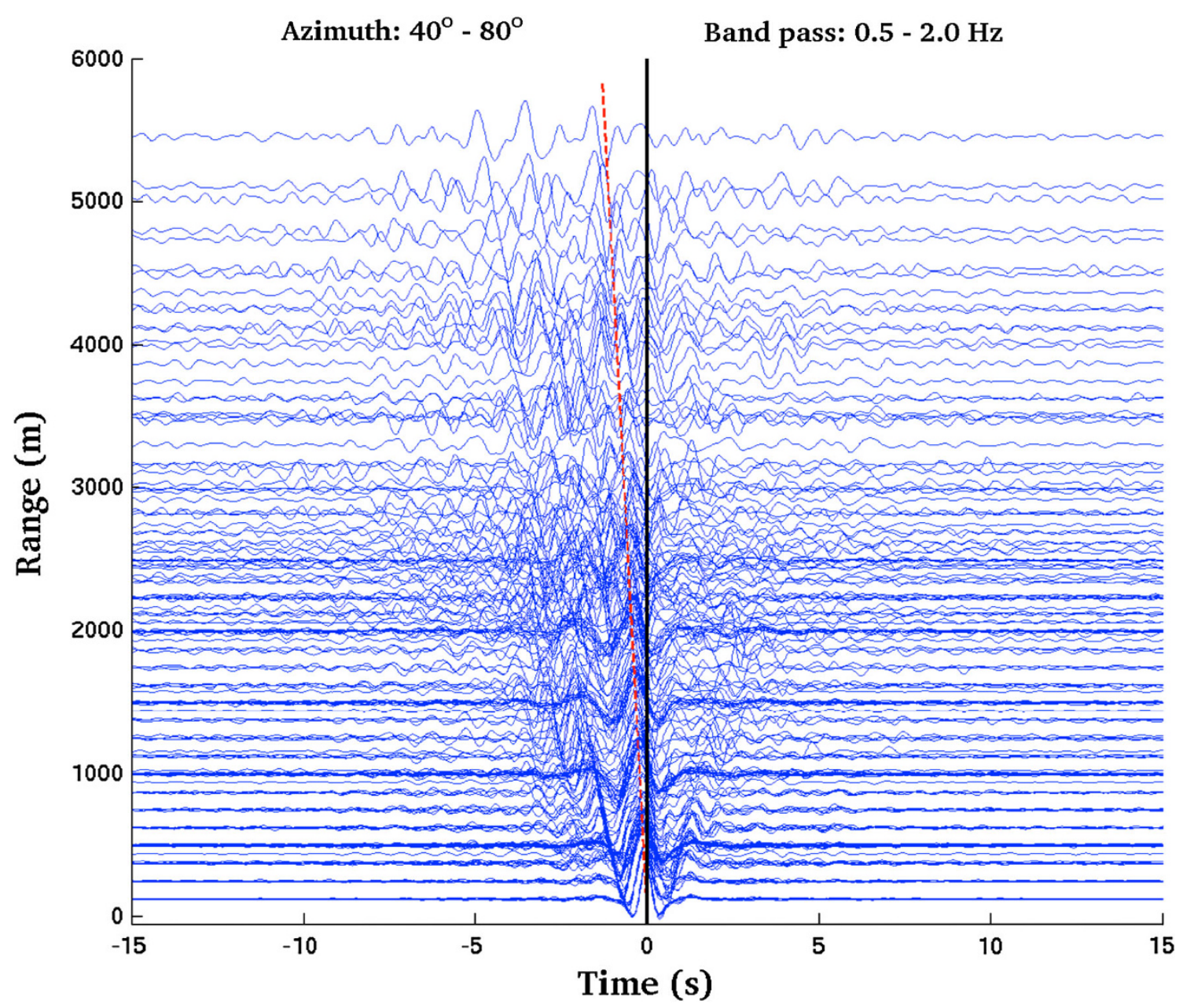

Fig. 2 Range-time representation of the vertical-component NCCs from the sensor pairs with an orientation between $40^{\circ}$ and $80^{\circ}$. The NCCs are daily calculated and stacked over 6 months. The frequency pass band is $0.5-2.0 \mathrm{~Hz}$. The dashed line indicates the arrivals at an apparent speed of $5 \mathrm{~km} / \mathrm{s}$

to ensure enough bandwidth of for NCCs to converge. For each pair of sensors, we calculate time derivatives of NCC outputs using daily segments, and then stack over days to analyze the converged arrivals.

\section{NCC results and a comparison with active shot records}

Previous studies have shown that the predominant seismic noise in southern California is microseism mainly coming from the Pacific Ocean (Gerstoft and Tanimoto 2007). At frequencies above $0.5 \mathrm{~Hz}$, Zhang et al. 2009 performed beamforming analysis and found that the noise field at the Calico fault experiment site contains strong and continuous $\mathrm{P}$ waves, which are generated offshore California as well. Specifically, the beamforming results show that the coherent P-wave energy arrives at the array from southwest (peak back-azimuth of $\sim 230^{\circ}$ ) at an apparent speed of $\sim 5 \mathrm{~km} / \mathrm{s}$. To focus on the main noise propagation direction, vertical-component NCCs (filtered between 0.5 and $2 \mathrm{~Hz}$ ) of the selected sensor pairs whose orientation lies between $40^{\circ}$ and $80^{\circ}$ are shown in Fig. 2. We observe propagating arrivals, both fast and slow, from the one-sided NCC outputs. The first arrival has an apparent speed of $\sim 5 \mathrm{~km} / \mathrm{s}$, confirming the observations from beamforming. The slower arrivals (speeds down to about $1.1 \mathrm{~km} / \mathrm{s}$ ) are likely the expected surface-wave Green's functions extracted from the diffused noise field.

An advantage of the Calico fault experiment is a sensor (D15T) deployed at essentially the same site (10 m apart) as an active shot. This allows the convergence of empirical Green's functions to be approved by directly comparing them with the shot records. Indeed, at frequencies of $0.8-1.6 \mathrm{~Hz}$, we observe a good match of the slower NCC arrivals and the shot waves (Fig. 3). In this comparison, the NCCs (blue) are constructed between the virtual source sensor D15T and a set of receivers that sample a range of 


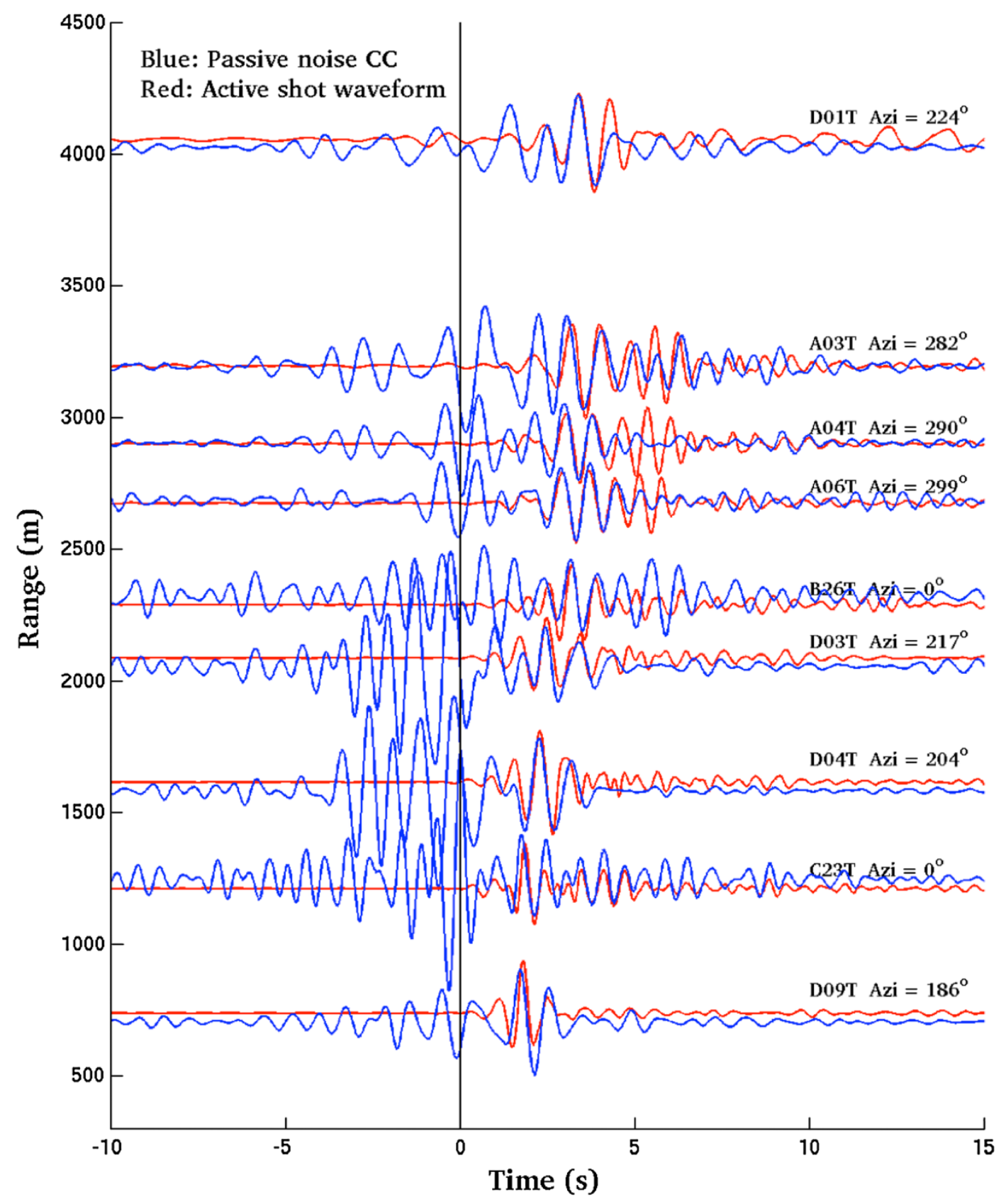

Fig. 3 Range-time representation of the vertical-component NCCs (blue) of the sensor pairs that share a common sensor (D15T), as well as the arrivals $(r e d)$ at these sensors from a borehole shot located near D15T. The frequency pass band is $0.8-1.6 \mathrm{~Hz}$

distance and azimuth, respectively. The seismograms of the shot (red) at the same set of receivers are plotted relative to the shot origin time.

One may notice in Fig. 3 that the apparent $P$ waves often arrive at near zero-lag time, and are independent of distances (i.e., non-propagating). This can be explained by a plane-wave approximation of the strong directional $\mathrm{P}$ waves. For example, as long as a pair of sensors has an orientation nearly perpendicular to the noise propagating direction, the P-wave energy, then arrives at the two sensors at about the same time, which ends up a NCC peak near zero-lag, independent of the separation distance of the two sensors. That is to say, one should distinguish apparent P-wave arrivals in NCC outputs (due to directional noise) from P-wave Green's functions due to a diffused noise field.

In Fig. 4, we further plot an example NCC output (D15T-A06T, also in Fig. 3) in frequency-time domain 
(a)

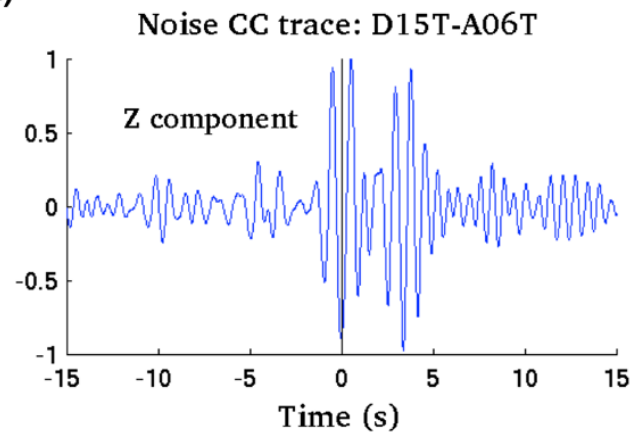

(c)

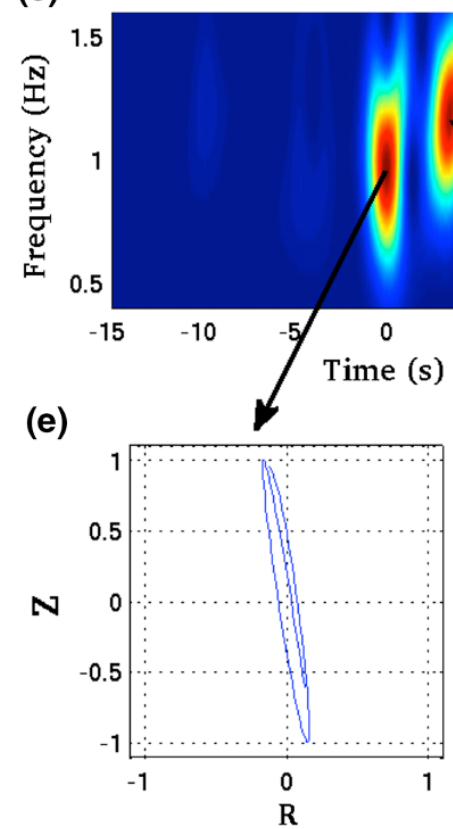

(f)

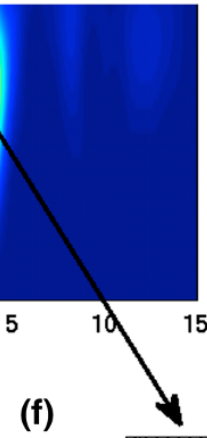

(b)

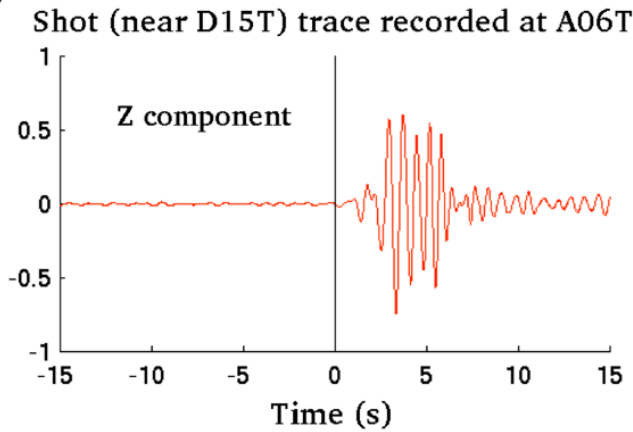

(d)
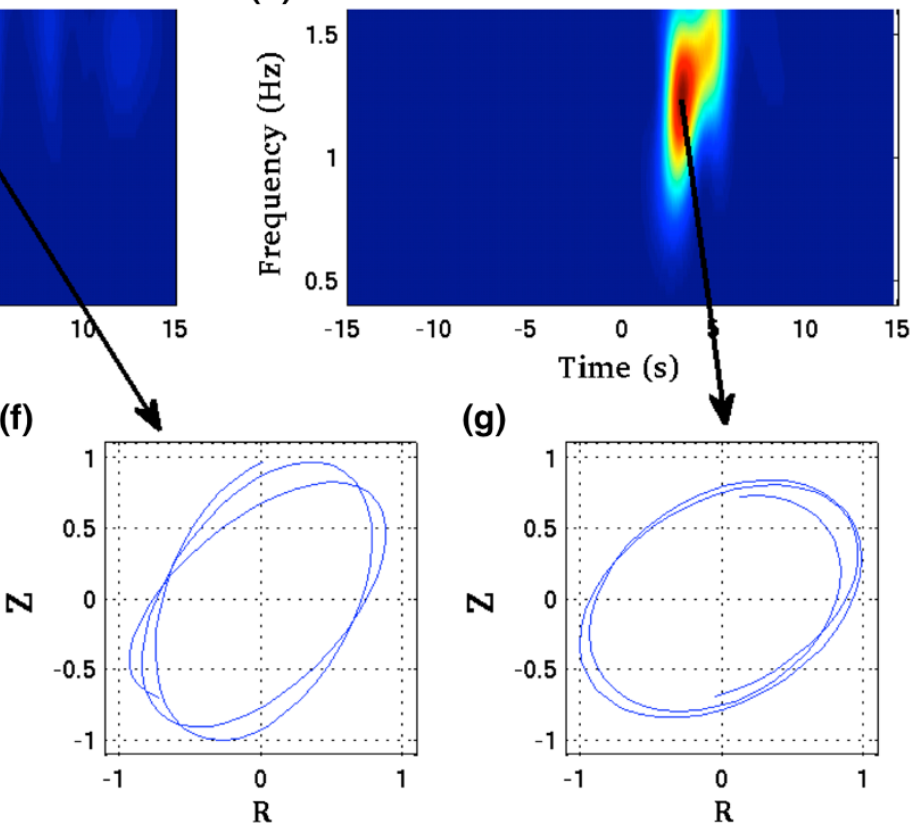

(g)

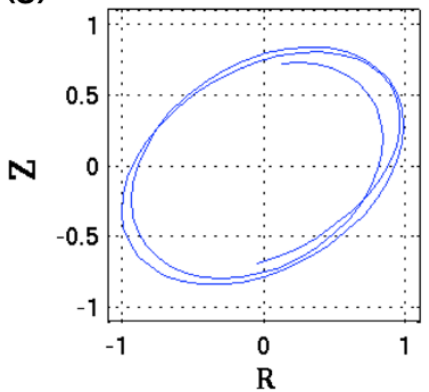

Fig. 4 Wave type analysis of the NCC of a sensor pair D15T-A06T, compared with that of the arrivals from a shot (near D15T) recorded at A06T. a The vertical-component NCC waveform daily calculated and stacked over 6 months. b The vertical-component of shot waveform. Note that the match of the waveforms of (a) and (b) can be seen in Fig. 3. c, d Frequency-time analysis of the waveforms shown in (a) and (b), respectively. Scale is for normalized power between 0 and 1. e-g Particle-motion plots of the two arrivals in (a), and the arrival in (b), respectively

and analyze particle motions of both the fast and the slow arrivals. Same analyses are performed for its comparable shot record (at A06T) as well. The NCC arrival at zerolag time appears non-dispersive (Fig. 4c) and arrives at a high angel with a P-wave-like particle motion (Fig. 4e). The slower NCC arrival is somewhat dispersive (Fig. 4c) but lacks higher frequency modes compared to the shot arrival (Fig. 4d). Its particle movement is similar to that of the shot arrival, showing a surface-wave motion (Fig. 4f, g). Nevertheless, the good match of the slower surface waves is encouraging in potential applications of the NCC technique at local scales, e.g., surface-wave isolation/removal for exploration purposes (Halliday et al. 2007).

\section{Low-velocity-zone observed from P-wave NCC arrivals}

Previous seismic studies using active shots and earthquakes recorded during the Calico fault experiment have concluded a relatively wide fault damage zone with reduced seismic velocities, i.e., low-velocity-zone (LVZ), along the Calico fault. Cochran et al. 2009 modeled the fault zone trapped waves (Ben-Zion and Aki, 1990; Li and Leary 1990) and estimated the Calico fault LVZ to be $1.5 \mathrm{~km}$ wide with velocities reduced by $40 \%-50 \%$. Yang et al. 2011 modeled the travel time delays of the direct and fault zone reflected waves across the fault zone and found that the Calico fault has a $1.3 \mathrm{~km}$ wide $\mathrm{LVZ}$ with $\mathrm{P}$ and $\mathrm{S}$ 
(a)

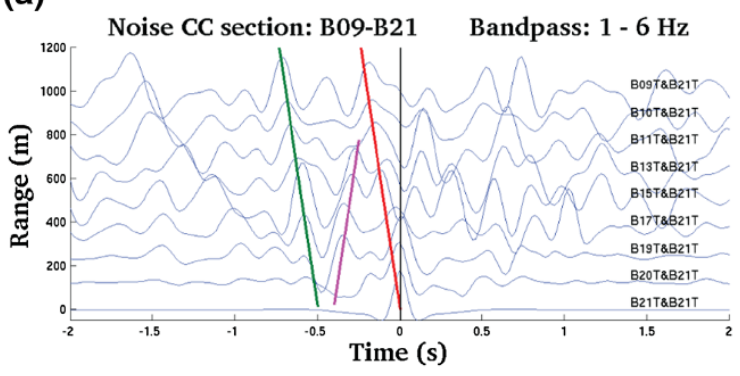

(b)

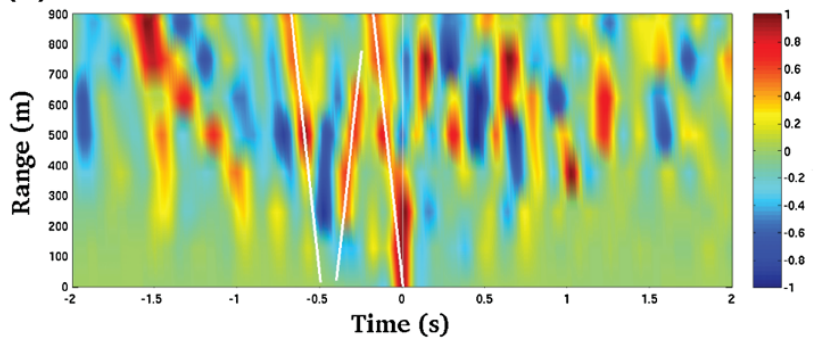

(c)

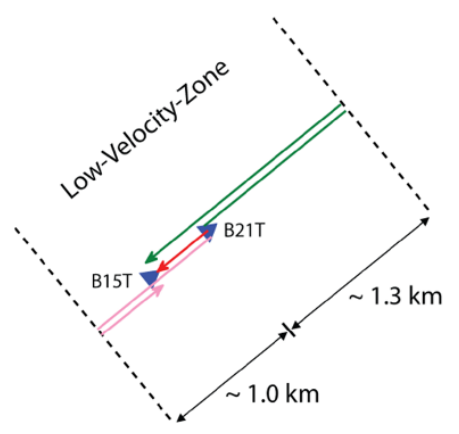

Fig. 5 Apparent P-wave reflections within the LVZ. a Range-time representation of the vertical-component NCCs for the profile B09TB21T, with B21T as the common sensor. The frequency pass band is 1-6 Hz. Lines of red, green, and magenta, respectively, mark the best-fit of the direct and reflected arrivals from the LVZ sidewalls, with an apparent speed of $5 \mathrm{~km} / \mathrm{s}$. b Same as (a), but with the waveform amplitudes shown in color scale, for normalized amplitude between -1 and 1 . White lines mark the direct and reflected arrivals. c A LVZ model showing the virtual arrivals from B15T to B21T, including the direct wave (red), the reflection from the east wall (green), and the reflection from the west wall (magenta)

velocity decreased $40 \%$ and $50 \%$, respectively. Alternatively, the InSAR observations suggested a $1-2 \mathrm{~km}$ wide LVZ with a shear modulus reduced by $50 \%$ (Fialko et al. 2002).

Yet another LVZ-meter would be to place a source and a profile of receivers within the $\mathrm{LVZ}$ and record reflections at normal incidence (vertical to the fault trace and LVZ walls). Thanks to a profile of dense sensors deployed nearly vertical to the fault trace, and to the strong body-wave noise source that constantly shoots energy to the array, we are able to use NCC to construct virtual shot arrivals and their reflections within the LVZ. Indeed, apparent P-wave reflections from NCCs have been observed in some other

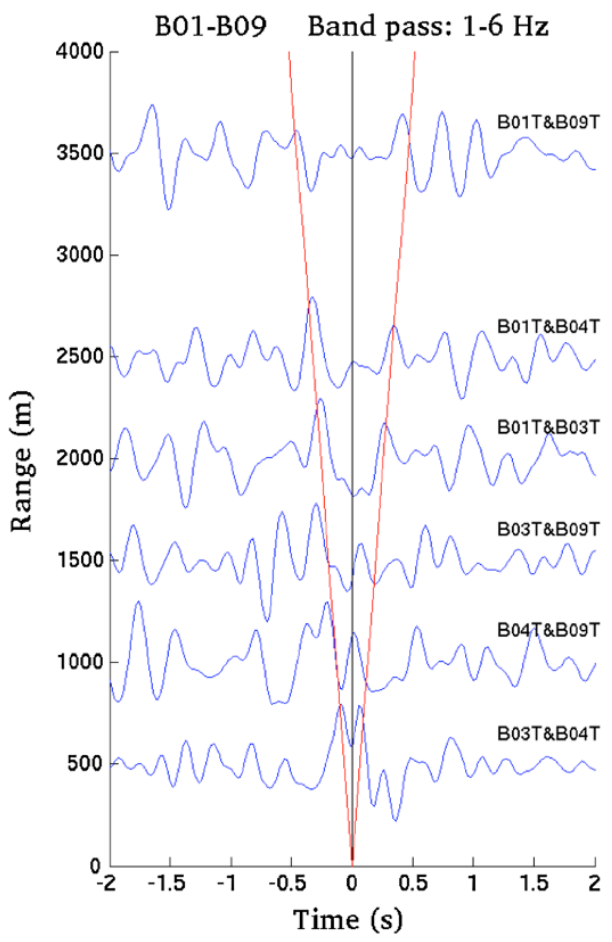

Fig. 6 Range-time representation of the vertical-component NCCs for the profile B01T-B09T. The frequency pass band is 1-6 Hz. The lines mark the best-fit of the first arrivals, with an apparent speed of $7.7 \mathrm{~km} / \mathrm{s}$

seismic experiments (Draganov et al. 2007; Chaput and Bostock 2007; Ryberg 2011).

Clear P-wave direct arrivals and their reflections, from a virtual source at each of sensors B09T-B20T to the sensor B21T, are observed from a range-time representation of the vertical-component NCCs (Fig. 5a, b). The frequency pass band is 1-6 Hz. The best-fitted apparent speed of both the direct phase and the two reflections is $5 \mathrm{~km} / \mathrm{s}$. The ray paths of the three arrivals are illustrated in a LVZ model shown in Fig. 5c. Namely, the apparent P-wave from a virtual source (e.g., B15T) is reflected back from both walls of the LVZ. Using the travel time differences between the direct arrival and its reflections shown in the NCC recordsection, we derive the distances from B21T to the reflectors (i.e., side walls of LVZ) to be $1 \mathrm{~km}$ (to the west wall) and $1.3 \mathrm{~km}$ (to the east wall), respectively. Thus, our estimate of the width of the Calico fault LVZ is $2.3 \mathrm{~km}$.

In addition, we construct vertical-component NCCs using a profile of sensors B01T-B09T (Fig. 6). They are located along the extension of the B09T-B21T profile but outside of the LVZ. Therefore, the first arrival observed from this profile provides an estimate of the apparent $\mathrm{P}$-wave speed outside of the LVZ, which amounts to $7.7 \mathrm{~km} / \mathrm{s}$. This suggests a velocity reduction of $35 \%$ (from 7.7 to $5 \mathrm{~km} / \mathrm{s}$ ) across the LVZ boundary, assuming the $\mathrm{P}$ waves from depth reach the LVZ and its outer range at a same angle. Note, 
however, that the apparent speeds we observed are not the estimates of P-wave velocities of the underground materials. In fact, one advantage of our method is that LVZ velocity is not needed. To measure LVZ width, one just needs to observe apparent speed across the array profile. Therefore, using NCC of body-wave noise is not subject to the trade-off between estimated width and material velocity, which could be significant when using fault zone trapped waves (BenZion 1998; Peng et al. 2003).

In general, our estimates of the LVZ width and velocity reduction within the LVZ are comparable with the results from previous studies (same order of magnitude), favorable to a relatively wide damage zone along the Calico fault. The width estimate is slightly larger than that of other studies ( 2.3 vs. $1.5 \mathrm{~km}$ ). The difference may be due to the intrinsic variations in the width along the fault. Our estimate represents the LVZ width only at the profile B09TB21T, while previous studies modeled the averaged LVZ width of a section of the fault. Our method does not resolve LVZ depth well. LVZ depth is perhaps best constrained by using high-frequency earthquake body waves and precursory phases (Yang and Zhu 2010). The application of our method also requires a dense line array deployment and sufficient directional body-wave noise energy. Lastly, although here we focus on body waves only, it is encouraging that one may also apply the NCC method to reconstruct probable trapped or guided waves for imaging fault zone structures (Hillers et al. 2013; Hillers 2013).

\section{Conclusions}

We calculate local-scale NCCs using seismic noise recorded at a small dense array deployed in the Calico fault experiment. At frequencies above $0.5 \mathrm{~Hz}, \mathrm{NCCs}$ are strongly contaminated by apparent $\mathrm{P}$ waves due to directional $\mathrm{P}$-wave noise generated offshore California. However, we observe a good match of the slow surface-wave NCC arrivals with the borehole shot arrivals that share the common source-receiver paths. This approves applications of the NCC technique for extracting reliable Green's functions at local scales. We also find that the NCC of a certain profile of sensors across the fault turns the directional $\mathrm{P}$-wave noise into apparent signals, including both direct arrivals and their reflections. These apparent phases allow us to estimate that the width of the Calico fault LVZ is $\sim 2.3 \mathrm{~km}$, and the velocity decreases by $\sim 35 \%$ within the LVZ.

\section{References}

Bensen GD, Ritzwoller MH, Shapiro NM (2008) Broad-band ambient noise surface wave tomography across the United States. J Geophys Res 113:B05306. doi:10.1029/2007JB005248
Ben-Zion Y (1998) Properties of seismic fault zone waves and their utility for imaging low velocity structure. J Geophys Res 103(12):567-585

Ben-Zion Y, Aki K (1990) Seismic radiation from an SH line source in a laterally heterogeneous planar fault zone. Bull Seism Soc Am 80:971-994

Campillo M, Paul A (2003) Long-range correlations in the diffuse seismic coda. Science 299:547-549

Chaput JA, Bostock MG (2007) Seismic interferometry using nonvolcanic tremor in Cascadia. Geophys Res Lett 34:L07304. doi:10.1029/2007GL028987

Chavez-Garcia FJ, Luzon F (2005) On the correlation of seismic microtremors. J Geophys Res 110:B11313. doi:10.1029/ 2005JB003671

Cochran ES, Li Y, Shearer PM, Barbot S, Fialko Y, Vidale JE (2009) Seismic and geodetic evidence for extensive, long-lived fault damage zones. Geology 37:315-318. doi:10.1130/G25306A.1

De Nisco G, Nunziata C (2011) Vs profiles from noise cross correlation at local and small scale. Pure Appl Geophys 168:509-520

Draganov D, Wapenaar K, Mulder W, Singer J, Verdel A (2007) Retrieval of reflections from seismic background-noise measurements. Geophys Res Lett 34:L04305. doi:10.1029/ 2006GL028735

Fialko Y, Sandwell D, Agnew D, Simons M, Shearer P, Minster B (2002) Deformation on nearby faults induced by the 1999 hector mine earthquake. Science 272:1858-1862

Gerstoft P, Tanimoto T (2007) A year of microseisms in southern California. Geophys Res Lett 34:L20304. doi:20310.21029/ 22007GL031091

Gerstoft P, Sabra KG, Roux P, Kuperman WA, Fehler MC (2006) Green's functions extraction and surface-wave tomography from microseisms in southern California. Geophysics 71:S123-S131

Gouedard P, Roux P, Campillo M (2008) Small-scale seismic inversion using surface waves extracted from noise cross correlation. J Acoust Soc Am 123. doi:10.1121/1.2838251

Halliday D, Curtis A, Robertsson JOA, van Manen D (2007) Interferometric surface-wave isolation and removal. Geophysics 72:A69-A73

Halliday D, Curtis A, Kragh E (2008) Seismic surface waves in a suburban environment. Lead Edge 27:210-218

Hillers G (2013) Noise based imaging of fault zone environments. In: 40th Workshop of the international school of geophysics on properties and processes of crustal fault zones, 18-24 May, Erice, Sicily

Hillers G, Ben-Zion Y, Landes M, Campillo M (2013) Interaction of microseisms with crustal heterogeneity: a case study from the San Jacinto fault zone area. Geochem Geophys Geosyst 14:2182-2197. doi:10.1002/ggge.20140

Li Y-G, Leary PC (1990) Fault zone trapped waves. Bull Seismol Soc Am 80:1245-1271

Lin F, Moschetti MP, Ritzwoller MH (2008) Surface wave tomography of the western United States from ambient seismic noise: Rayleigh and Love wave phase velocity maps. Geophys J Int. doi:10.1111/j1365-246X.2008.03720.x

Liu X, Ben-Zion Y (2013) Theoretical and numerical results on effects of attenuation on correlation functions of ambient seismic noise. Geophys J Int 194:1966-1983. doi:10.1093/gji/ggt215

Lobkis OI, Weaver RL (2001) On the emergence of the Green's function in the correlations of a diffuse field. J Acoust Soc Am 110:3011-3017

Nuziata C, De Nisco G, Panza GF (2009) S-waves profiles from noise cross correlation at small scale. Eng Geol 105:161-170

Peng Z, Ben-Zion Y, Michael AJ, Zhu LP (2003) Quantitative analysis of seismic fault zone waves in the rupture zone of the Landers, 1992, California earthquake: evidence for a shallow trapping structure. Geophys J Int 155:1021-1041 
Rickett J, Claerbout J (1999) Acoustic daylight imaging via spectral factorization: Helioseismology and reservoir monitoring. Lead Edge 18:957-960

Roux P, Kuperman WA, the NPAL Group (2004) Extracting coherent wavefronts from acoustic ambient noise in the ocean. J Acoust Soc Am 116:1995-2003

Roux P, Sabra KG, Gerstoft P, Kuperman WA, Fehler MC (2005) P-waves from cross-correlation of seismic noise. Geophys Res Lett 32:L19303. doi:10.1029/2005GL023803

Ryberg T (2011) Body wave observations from cross-correlations of ambient seismic noise: a case study from the Karoo, RSA. Geophys Res Lett 38:L13311. doi:10.1029/2011GL047665

Sabra KG, Gerstoft P, Roux P, Kuperman WA, Fehler MC (2005a) Extracting time-domain Greens function estimates from ambient seismic noise. Geophys Res Lett 32:L03310. doi:10.1029/ 2004GL021862

Sabra KG, Gerstoft P, Roux P, Kuperman WA, Fehler MC (2005b) Surface wave tomography from microseism in Southern California. Geophys Res Lett 32:L14311. doi:10.1029/2005GL023155

Shapiro NM, Campillo M (2004) Emergence of broadband Rayleigh waves from correlations of the ambient seismic noise. Geophys Res Lett 31:L07614. doi:10.1029/2004GL019491

Shapiro NM, Campillo M, Stehly L, Rizwoller MH (2005) Highresolution surface wave tomography from ambient seismic hoise. Science 307:1615-1617
Snieder R (2004) Extracting the Green's function from the correlation of coda waves: A derivation based on sensorary phase. Phys Rev E 69:046610

Wang W, Ni S, Wang B (2010) Composition of high frequency ambient noise from cross-correlation: a case study using a small aperture array. Earthq Sci 23:433-438

Weaver RL (2013) On the retrieval of attenuation and site amplifications from ambient noise on linear arrays: further numerical simulations. Geophys J Int. doi:10.1093/gji/ggt063

Yang H, Zhu L (2010) Shallow low-velocity zone of the San Jacinto fault from local earthquake waveform modelling. Geophys J Int 183:421-432. doi:10.1111/j.1365-246X.2010.04744.x

Yang Y, Ritzwoller MH, Levshi AL, Shapiro NM (2007) Ambient noise Rayleigh wave tomography across Europe. Geophys J Int 168:259-274

Yang H, Zhu L, Cochran ES (2011) Seismic structures of the Calico fault zone inferred from local earthquake travel time modeling. Geophys J Int 186:760-770

Yao H, van der Hilst RD, de Hoop MV (2006) Surface-wave array tomography in SE Tibet from ambient seismic noise and two-sensor analysis: I. Phase velocity maps. Geophys J Int 166:732-744

Zhang J, Gerstoft P, Shearer PM (2009) High-frequency P-wave seismic noise driven by ocean winds. Geophys Res Lett 36:L09302. doi:10.1029/2009GL037761 